\title{
SIMULATION OF A QUAY WALL FOUNDATION ON AN IMPROVED SEABED. THE EXAMPLE OF THE NEW PORT OF PATRAS
}

\author{
Botsou I. ${ }^{1}$, Botsou M. ${ }^{1}$ and Loupasakis C. ${ }^{1}$ \\ ${ }^{I}$ National Technical University of Athens, School of Mining and Metallurgical Engineering, \\ Department of Geological Sciences, Zografou Campus, GR-157 80 Athens, Greece, \\ ioannabotsou@hotmail.com,mariabotsou@hotmail.com,cloupasakis@metal.ntua.gr
}

\begin{abstract}
The current study examines the possibility of simulating a quay wall foundation on a gravel pile improved seabed by using the finite element method. For this purpose data from the construction of the New Port of Patras were used. The behavior of the construction was simulated by conducting a series of parametric analyses altering the length and the density of the gravel piles as well as the gradient and the volume of the preloading embankment. Important conclusions regarding the safety factor and the deformations rate of the construction were finally extracted. The simulations were conducted by using PLAXIS $2 D$.
\end{abstract}

Keywords: quay wall, gravel piles, preloading embankments, finite elements simulation.

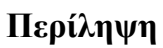

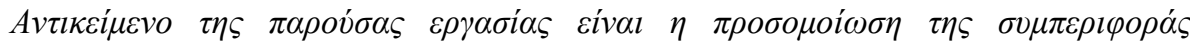

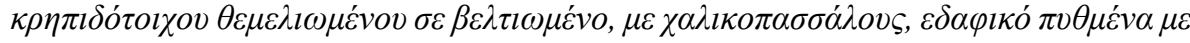

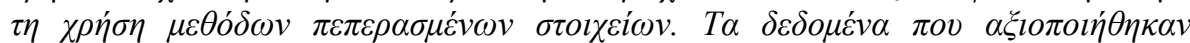

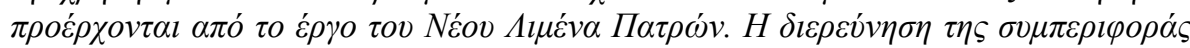

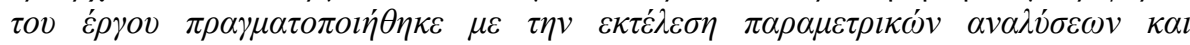

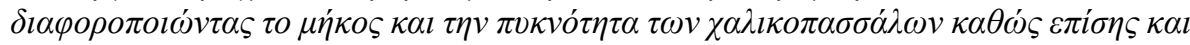

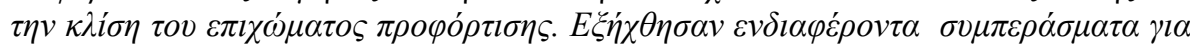

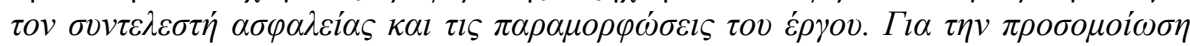

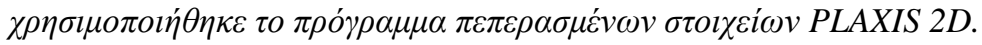

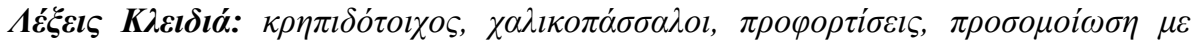

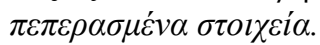

\section{Introduction}

The project of the New Port of Patras is a very significant infrastructure project. The aim of this project is to connect Greece with the rest of Europe and to satisfy key strategic objectives of the country for alternative international connections. Due to the importance of the project and the well founded study it was considered important to take the chance and conduct a series of parametric simulations in order to see the efficiency of the structure when changing crucial parameters of its geometry. For the simulation of the construction the PLAXIS finite element program was used. At this point it should be noted that all FEM simulation presented have no relation to the original study 
of the project. The original project reports were used only for their geotechnical data as well as for extracting some general guidelines regarding the geometry of the construction.

\section{The study area - geological and geotechnical setting}

The foundation formations of the quay wall are recent seafloor sentiments, mainly fine grained. The stratigraphy of the sediments was examined in detail by geotechnical drilling. As presented in figure 1 the top layer, 5 to $8 \mathrm{~m}$ thick, consists of loose watery clay. Underneath a thin sand layer extending for 1.5 to $3 \mathrm{~m}$ is located, presenting poor mechanical properties. The deeper strata consist of clays with gradually improving mechanical properties. Clays with sufficient stiffness were located approximately $23 \mathrm{~m}$ below seafloor.

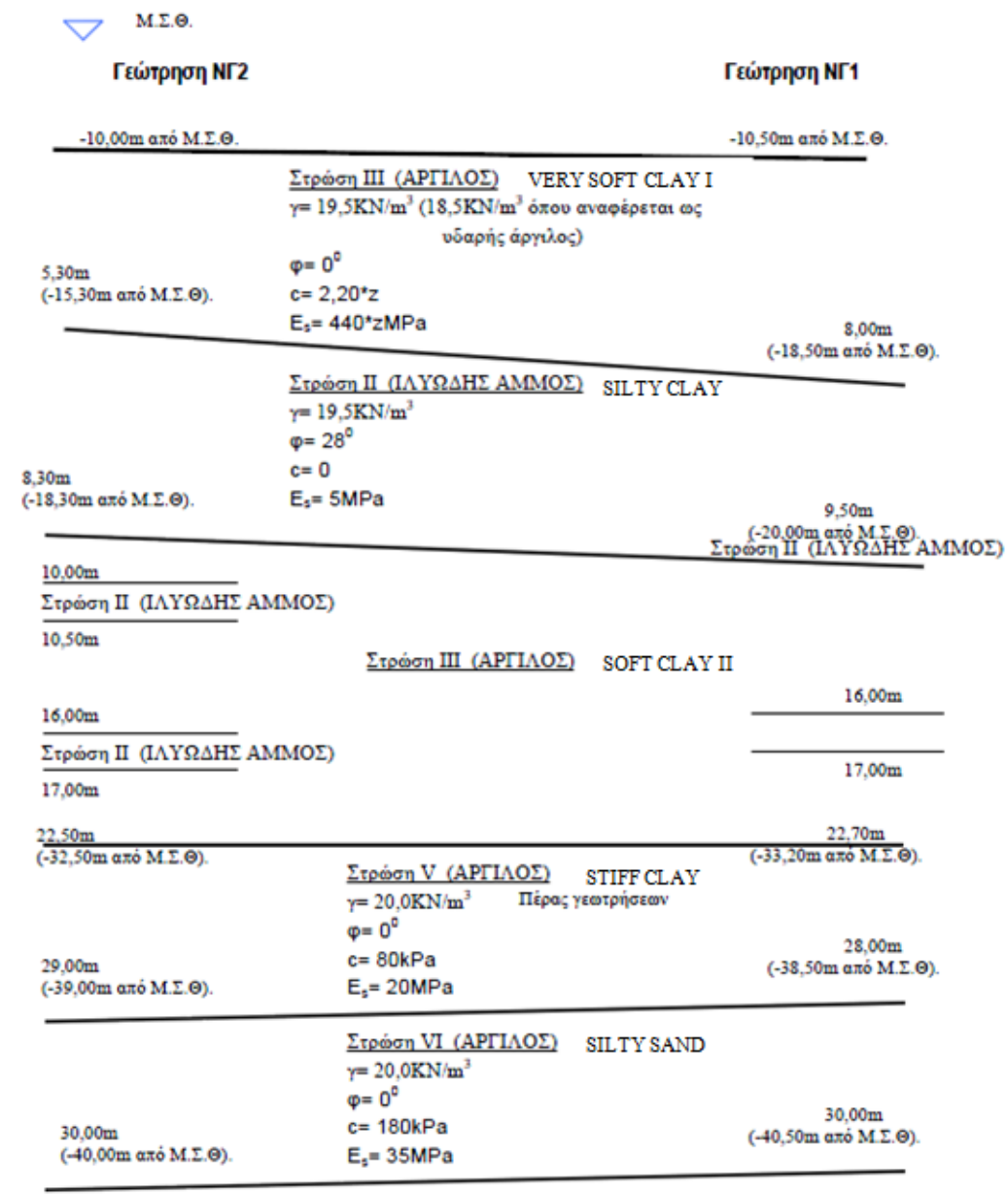

Figure 1 - Layering of the area of the New Port of Patras.

The project's site is intersected by two faults, which are classified as active (Koukis, 2005; Ori, 1989). Considering the seismotectonic regime of the site the existence of the faults is a main factor to be considered in regards to the seismic design of the project. These two faults are (Figure 2):

- The fault of "Glaucos", which borders the construction area of the project and

- The fault of "Agia Triada", which cuts across the project site.

Another characteristic phenomenon linked to the seismic activity along the fault zones is the existence of craters, called "pock-holes". Their creation is probably due to the sudden expansion of 
gases which are trapped under pressure in deeper horizons, created by the protracted decay of organic substances, frequent in lacustrine or lagoonal environments. Their diameter ranges from a few centimeters to about $200 \mathrm{~m}$ and their depth reaches $15 \mathrm{~m}$ (Marinaro et al., 2006).

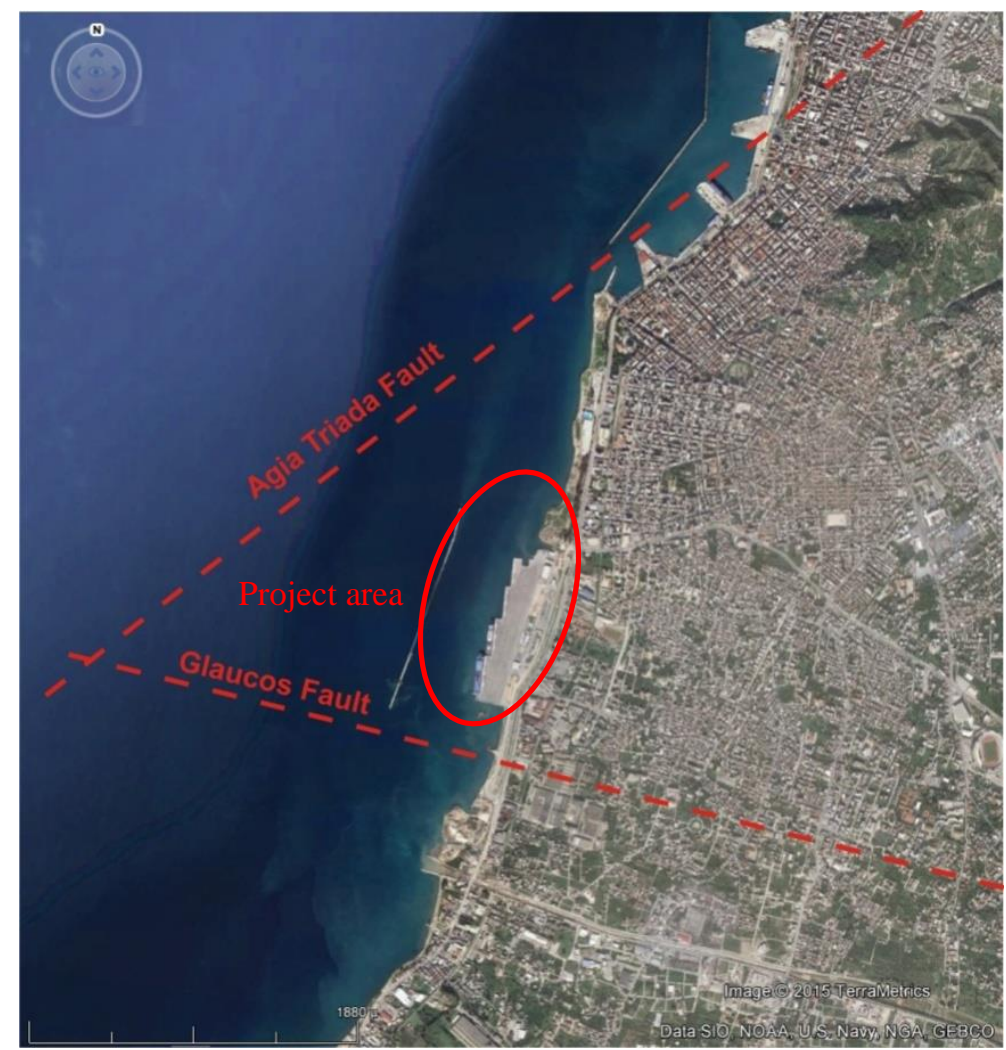

\section{Figure 2 - The location of the "Agias Triada" and "Glaucos" faults in relation to the New Port of Patras.}

Summarizing, the geotechnical conditions in the project area are particularly adverse because of the very soft surface layer, the increased seismic activity of the region and the presence of the active vertical seismic faults and finally the presence of a significant number of craters "pock-holes".

\section{Project design}

Due to unfavorable geotechnical conditions and the seismicity of the region, it was decided by the project planning team that the safest option for the construction of the port is the solution of a light quay, with caissons (Figure 3) and a light weight backfill, in preloaded ground reinforced with gravel piles (Figure 4).

The project design combines (TRITON et al., 2007, 2012a, 2012 $2^{\mathrm{b}}$ ):

- The improvement and reinforcement of the upper very soft clay-alluvium layer with compacted gravel piles, in a $2.75 \times 2.75 \mathrm{~m}$ grid, constructed by the method of bottom feed (Figure 3-A).

- The preloading of the area of the foundation with gradually constructed embankment (Figure 3-B).

- The construction of the platform with prefabricated floating cellular boxes of reinforced concrete (caissons) (Figure 3-C). They offer the advantages of a low weight, adjustable quay, avoiding the construction of deep foundation. 
However, the use of caissons does not provide acceptable safety factors; therefore in order to decrease the horizontal loads to the quay as well as to the foundation, a backfill from pumice, with zero bulk density was installed.
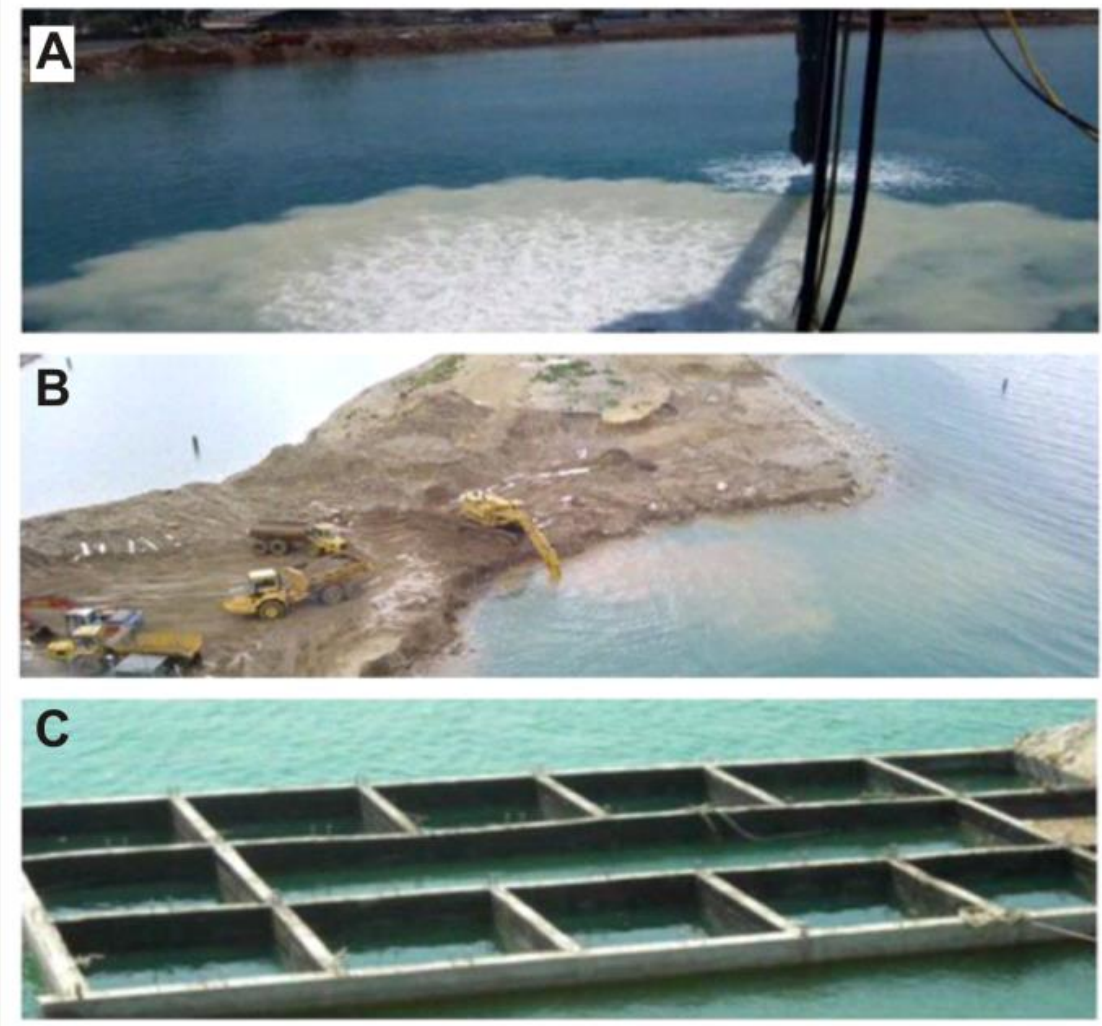

Figure 3 - A. The vibrating head used in the construction of the gravel piles. B. The construction of the preloading embankment. $C$. The caisson.

\section{Simulation procedure - parametric analyses}

The simulation of the construction was divided in 8 calculation phases. During the first phase the foundation formations including the piles were activated and loaded using the "Gravity Loading" procedure. During the four next phases the preloading embankment was gradually constructed and the loading was applied. These phases were simulated by applying consolidation analysis. At the following phases the upper part of the preloading embankment was removed and then the caissons as well as the backfill prisms were installed. Phi/c reduction calculation steps were also included for the estimation of the safety factor.

The cross section and the mechanical properties of the model are clearly presented in Figure 4 and Table 1, respectively. This simulation was also conducted for various pile lengths. 


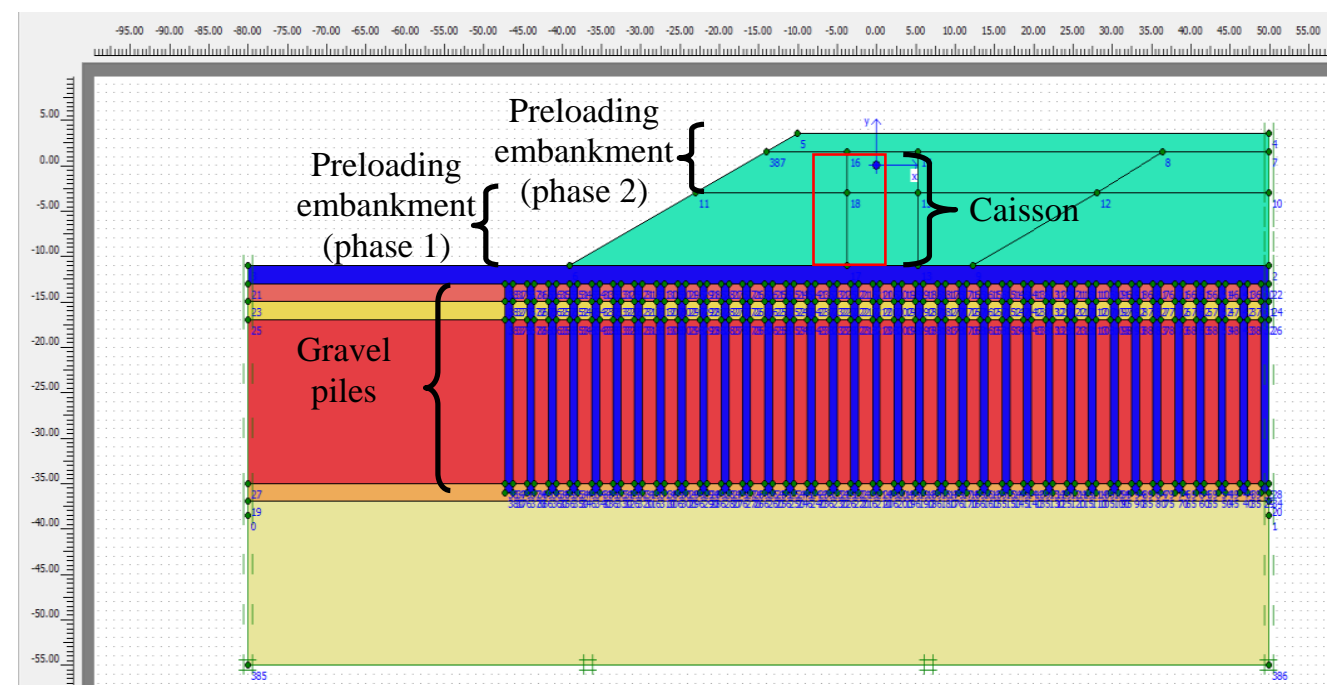

Figure 4 - The cross section of the quay wall as introduced at the simulation program.

Table 1 - Mechanical properties of the materials, as reported at the original geotechnical study (TRITON et al., 2007, 2012 ${ }^{\mathrm{a}}$ 2012 $^{\mathrm{b}}$ ).

\begin{tabular}{|l|c|c|c|c|c|c|c|}
\hline & $\begin{array}{c}\gamma \mathbf{S a t} \\
(\mathbf{k N / m 3 )}\end{array}$ & $\mathbf{c}^{\prime}(\mathbf{k P a})$ & $\mathbf{\Phi}^{\prime}\left(^{\mathbf{0}}\right)$ & $\mathbf{E s}(\mathbf{k P a})$ & $\begin{array}{c}\mathbf{k x}=\mathbf{k y} \\
\mathbf{m} / \mathbf{d a y})\end{array}$ & $\mathbf{v}$ & $\begin{array}{c}\text { Material } \\
\text { model }\end{array}$ \\
\hline $\begin{array}{l}\text { Embankment } \\
\text { material }\end{array}$ & 19 & 0 & 33 & 10000 & 600 & 0.3 & M-C* \\
\hline Gravels & 20 & 0 & 35 & 10000 & 2500 & 0.3 & M-C* \\
\hline $\begin{array}{l}\text { Very Soft } \\
\text { clay I }\end{array}$ & 18.5 & 30 & 18 & 5700 & 0.00864 & 0.35 & M-C* \\
\hline Silty Clay & 19.5 & 10 & 28 & 19000 & 0.0864 & 0.3 & M-C* \\
\hline Soft Clay II & 18.5 & 37 & 18 & 7500 & 0.00864 & 0.35 & M-C* \\
\hline Stiff Clay & 20 & 200 & 20 & 20000 & 0.000864 & 0.3 & M-C* \\
\hline Silty Sand & 20 & 35 & 30 & 14500 & 8.64 & 0.3 & M-C* \\
\hline
\end{tabular}

*M-C: Mohr - Coulomb model

Applying the aforementioned simulation procedure the following three series of parametric simulations were conducted (Figure 6):

1) Simulations examining the effect of the gravel piles length. Three different pile lengths of 8 , $15,23 \mathrm{~m}$ were selected.

2) Simulations examining the effect of the gravel piles density. Three different settings considering that 55, 22 and $13 \%$ of the area was replaced by gravel piles were simulated. This simulations was conducted for various pile lengths also.

3) Simulations examining the effect of the embankment's slope dip angle. Keeping the pile $23 \mathrm{~m}$ in length, the dip angle of the slopes was changed from $50 \%$ to $43 \%$ and finally to $40 \%$.

The estimation and the comparison of the safety factors and the displacement values were the main aspects of these simulations. 


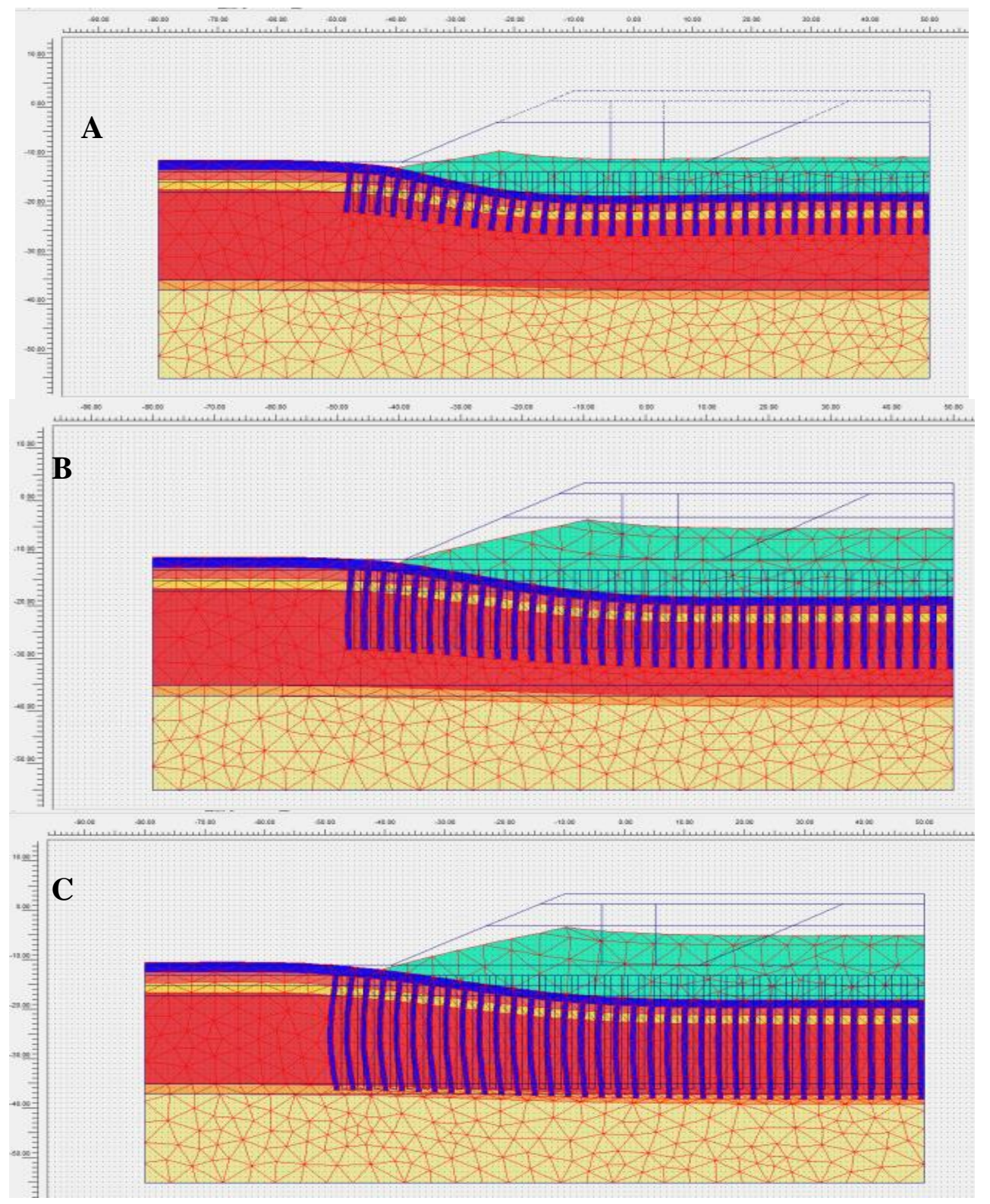




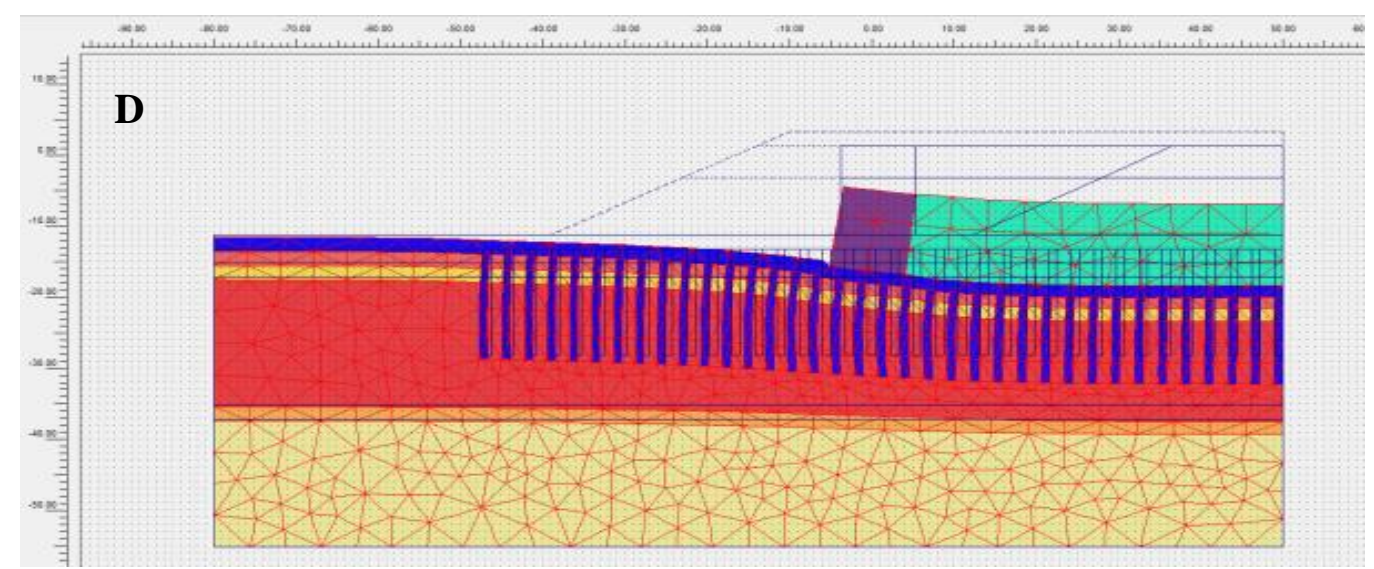

Figure 5 - A. Screen snapshot of the simulation displaying the deformed mesh after the first construction stage of the preloading embankment B. Screen snapshot of the simulation displaying the deformed mesh after the preloading phase is completed, for the $15 \mathbf{m}$ gravel piles $\mathrm{C}$. Screen snapshot of the simulation displaying the deformed mesh after the preloading phase is completed, for the $\mathbf{2 3} \mathrm{m}$ gravel piles $\mathrm{D}$. Screen snapshot of the simulation displaying the deformed mesh at the last phase of the simulation, after the installation of the caisson and the completion of the embankment.

\section{Simulation results - discussion}

Summarizing, the conclusions resulting from the parametric simulations are the following.

- As expected, increasing the length of the gravel piles, smaller total displacements get calculated at all calculation phases. The same conclusion arises also when increasing the density of the piles. This result occurs due to the fact that in both cases the percent of the replaced - improved material increases.

- Increasing the length of the gravel piles from 15 to 23 m causes a notable decrease in total displacements, in relation to the decrease noticed when increasing the length from 8 to $15 \mathrm{~m}$. This is because when increasing the length of the gravel piles down to the depth of $23 \mathrm{~m}$ the improvement extends covering the entire length of the soft clay layer.

- The flattening of the preloading embankment slopes causes significant reduction at the total displacements of the preloading embankment and a proportional increase of the safety factor. This benefits only the construction period as at the final construction the geometry is defined by the caissons.

- As in all parametric simulations the safety factor was adequate, the final design of the project should be decided considering economotechnical parameters.

\section{Acknowledgments}

I sincerely thank the construction team of the New Port of Patras and the construction company, AKTOR, for providing all the necessary data.

\section{References}

Koukis, G., Sabatakakis, N., Tsiambaos, G. and Katrivesis, N., 2005. Engineering geological approach to the evaluation of seismic risk in metropolitan regions: case study of Patras, Greece, Bull. Eng. Geol. Environ., 64, 219-235.

Marinaro, G., Etiope, G., Lo, N., Favali, P., Papatheodorou, G., Christodoulou, D., Furlan, F., Gasparoni, F., Ferentinos, G., Masson, M. and Rolin, J.-F., 2006. Monitoring of a methane- 
seeping pockmark by cabled benthic observatory (Patras Gulf, Greece), Geo-Mar Lett, 26, 297-302.

Ori, G.G., 1989. Geologic history of the extensional basin of the Gulf of Corinth (MiocenePleistocene), Greece, The Geological Society of America, Geology, 17, 918-921.

TRITON, BETAPLAN, DENCO, ADK, Milionis, N. and Kokoromitis A., 2007. Evaluation report of the geotechnical research results. Unpublished technical report, Athens.

TRITON, BETAPLAN, DENCO, ADK, Milionis, N. and Kokoromitis, A., 2012 ${ }^{\mathrm{a}}$. final study of the $3^{\text {rd }}$ section of the Patra harbor. Unpublished technical report, Athens.

TRITON, BETAPLAN, DENCO, ADK, Milionis, N. and Kokoromitis, A., 2012 $2^{\mathrm{b}}$. final study of the $3^{\text {rd }}$ section of the Patra harbor- sub-part 6: final foundation study. Unpublished technical report, Athens. 